\title{
Análise praxeológica de livro didático de computação referente ao estudo de números binários
}

\section{RESUMO}

Herman do Lago Mendes herman2000@zipmail.com.br 0000-0001-5631-1578

Secretaria Estadual de Educação de Sergipe, Aracaju, Sergipe, Brasil.
Objetiva analisar as organizações praxeológica computação e praxeológica didática de um livro de ciência da computação à nível de ensino fundamental referente ao estudo de números binários. Recorre à Teoria Antropológico do Didático (TAD) de Yves Chevallard como referencial teórico e mais especificamente, um de seus conceitos, praxeologia, como ferramenta metodológica de pesquisa. A partir da definição de problemas de pesquisa, tipos de tarefas referentes ao estudo de números binários estão claramente expostos e bem identificados? As técnicas são exemplificadas, justificadas, teorizadas e relacionadas com essas tarefas? Conclui que a abordagem dos números binários caracteriza-se como sendo uma praxeologia regional. Identifica 20 tipos de tarefas, 7 técnicas, 5 tecnologias e 1 princípio de uma teoria (teoria da informação e comunicação de Shannon).

PALAVRAS-CHAVE: Números Binários. Praxeologia. Livro didático de computação. 


\section{INTRODUÇÃO}

Com o advento da informatização da sociedade, a presença de aspectos relativos à representação binária do número tem aumentado. O sistema de numeração binário (base 2) é uma representação de número assim como o sistema de numeração decimal (base 10). Ou seja, recorre apenas a dois dígitos, 0 ou 1, para representar qualquer número; utiliza-se todas as características do sistema de numeração de base 10, porém, configura-se como base o 2, cada algarismo, 0 ou 1 , a depender de sua posição, passa a representar o seu valor absoluto multiplicado pela potência de 2 relativa à posição enumerados da direita para a esquerda.

Os números binários são utilizados atualmente como elementos necessários e fundamentais na comunicação entre computadores eletrônicos digitais por serem utilizados como representação de número (sequências de 0s e 1s) em codificações de caracteres, de vídeos, etc.

Mendes (2015) analisou a organização praxeológica matemática e praxeológica didática referente aos números binários de uma coleção de livros didáticos de matemática do ensino fundamental avaliado pelo Programa Nacional do Livro Didático (PNLD 2014) e constatou que a sua abordagem caracteriza-se como sendo uma praxeologia pontual e local: identificando 3 tipos de tarefas, 3 técnicas, uma única tecnologia e nenhuma teoria.

Os números binários (que por sinal fazem parte de um conteúdo da ciência Matemática) mantém uma organização praxeológica em livro didático de computação? Caso exista, tipos de tarefas referentes ao estudo de números binários estão claramente expostos e bem identificados? As técnicas são exemplificadas, justificadas, teorizadas e relacionadas com essas tarefas? A partir destes problemas de pesquisa, objetivamos analisar as organizações praxeológica computação e praxeológica didática referente ao estudo de números binários em livro didático de computação referente ao nível fundamental de ensino. Utilizamos a Teoria Antropológica do Didático (TAD) tanto para fundamentar teoricamente este trabalho como ferramenta de pesquisa. Mais especificamente, utilizamos um dos conceitos da TAD - praxeologia - como ferramenta de pesquisa.

Praxeologia ou organização praxeológica é um elemento conceitual da TAD. Por um olhar etimológico, a palavra praxeologia deriva de duas palavras gregas, práxis e logos; que partem de princípios inter-relacionados na ação humana em realizar algum fim: práxis significa a parte prática, enquanto o logos significa a parte inteligível, racional e lógico, caracterizado pela teoria. Desta maneira, a praxeologia mantém relação e imbricação de conjuntos de elementos práticos e teóricos em qualquer tipo de ação humana (BOSCH, GASCÓN, 2005). "A práxis implica o logos, que por sua vez faz o backup de práxis" (CHAVELLARD, 2007, p.3, tradução nossa). Ou seja, existe uma tese de que não podem existir ações humanas sem ser, ao menos, explicadas (parcialmente), feitas (de maneira inteligível), por alguma explicação ou justificação (ibidem). "Dessa maneira, toda a práxis requer um apoio no logos porque nenhum fazer humano permanece sem ser questionado" (BOSCH, GASCÓN, 2007, pp.397, 398 tradução nossa). 
A noção de tarefa é a raiz da noção de praxeologia. O conceito de tarefa é amplo segundo a TAD. Um simples piscar os olhos já é considerado uma tarefa. Geralmente, uma tarefa t pertence a um tipo de tarefa $\mathrm{T}(\mathrm{t}$ I T) ou seja, na maioria dos casos uma tarefa é um tipo de "tarefa pai" e é expresso por um verbo: lavar roupa, codificar um texto, pentear os cabelos, etc. Destaquemos que o conceito de tarefa, ou melhor de tipo de tarefa, requer um propósito relativamente específico (CHEVALLARD, 1998); tarefas e tipos de tarefas são produções, "artefatos", "obras" humanas intencionadas (ibidem). Portanto, tarefa ou tipo de tarefa está relacionada ao "fazer coisas".

A tarefa pode ser executada, realizada de diversas formas. Essa dinâmica proporcionada em fazer a tarefa é chamada pela TAD de técnica. Esta é considerada como a "arte", um saber comum, surgida do grego techne. Assim, uma praxeologia sobre um tipo de tarefa T contém, em princípio, uma técnica em T. Estes dois elementos da praxeologia é definido por Chevallard (1998) como sendo um bloco prático-técnico [ $\mathrm{T}$, ,]. Portanto, técnica é o "como fazer" de determinado tipo de tarefa. Exemplo: Astrogildo dorme de bucho para baixo. Primeiro ele pega um travesseiro e um lençol. Em seguida ele se enrola com o lençol, posiciona a cabeça no travesseiro e deita de bucho para baixo. Berivaldo dorme de lado. Primeiro ele pega dois travesseiros. Em seguida posiciona-se de lado na cama pondo a cabeça em um travesseiro e o outro travesseiro coloca entre as pernas. Astrogildo e Berivaldo dormem de maneiras diferentes (técnicas diferentes), mas mantêm o mesmo tipo de tarefa: dormir.

Por que Berivaldo dorme de lado utilizando de dois travesseiros? Ele poderia responder: para que a minha coluna fique alinhada; tanto a minha cabeça quanto os meus pés fiquem na altura do meu coração, melhorando a minha circulação sanguínea. Esta justificativa e explicação da técnica utilizada por Berivaldo é chamado por Chevallard de tecnologia . Este é outro elemento praxeológico que é definido como a explicação e justificação, de maneira racional (logos), da técnica. A função da tecnologia é justificar a veracidade da técnica; explicar, de maneira inteligível, determinada técnica como também explicar o seu porquê. Em muitos casos, elementos tecnológicos são integrados na arte. Portanto, tecnologia esta relacionada ao "por que fazer coisas de determinada maneira?". Ela é intrínseca, entrelaçada com a técnica.

Por que o corpo estando alinhado melhora a circulação sanguínea? Uma explicação ainda racional dessa justificativa poderia ser dada por meio de teorias referentes à circulação sanguínea. Assim, o discurso tecnológico contém afirmações que pode conter porquês. E a partir destes porquês, ao maior nível de explicação dela, surge mais um elemento da organização praxeológica chamada por Chevallard (1998) de teoria . "A teoria refere-se a um conjunto mais abstrato de conceitos e argumentos dispostos em um discurso geral que justifica a tecnologia em si" (MERTENSEN, 2011, p.218). A teoria é entrelaçada a tecnologia e ambas são definidas como sendo um bloco tecnológico-teórico [ , ] (CHEVALLARD, 1998).

Segundo Mertensen (2011) o modelo praxeológico foi recentemente utilizado para a análise de intervenção de ensino em contextos formais de educação científica. Como uma das principais contribuições, temos a identificação e remediação de dissociação entre teoria e prática dos corpus de conhecimentos ensinados. 
Nesta pesquisa, iremos abordar praxeologias computação e didática relativas às atividades de números binários, fazendo um levantamento técnico, tecnológico, teórico e prático (tarefas) do objeto de estudo de números binários. Ou seja, iremos caracterizar as praxeologias computação e didática referentes ao corpus de estudos de números binários no livro didático de computação.

A organização praxeológica computação e a organização praxeológica didática são organizações imbricadas. Ou seja, essa primeira praxeologia parte de um tratamento didático imbricado com qualquer que seja as preocupações didáticas e epistemológicas: seleção, organização, planejamento, método, por exemplo.

Chevallard (1998) define quatro categorias de organizações praxeológicas: praxeologia pontual, praxeologia local, praxeologia regional e praxeologia global. A princípio, um tipo de tarefa T é formado por uma técnica, uma tecnologia e uma teoria, todos estes denotados por praxeologia pontual [T, , , ]. A praxeologia pontual apenas leva em consideração uma única tarefa $\mathrm{T}$. A praxeologia local [Ti, $i$, , ] leva em consideração uma determinada tecnologia . A praxeologia regional $[T i j, i j, i$,$] leva em consideração uma determinada teoria ; várias tecnologias j,$ que cada qual por sua vez justifica e torna-se inteligível; várias técnicas ij, que correspondem ao maior número de tipos de tarefas Tij. Quando a organização praxeológica é desenvolvida em uma determinada instituição I pela agregação de várias tarefas Tij, técnicas ij e tecnologias ij à várias teorias i, é chamada de praxeologia global [Tijk, ijk, ijk, k]. Ou seja, a praxeologia global é a agregação de várias organizações praxeológicas regionais atuantes às várias teorias .

Da passagem da praxeologia pontual à praxeologia local a tecnologia é enfatizada. De maneira semelhante, da passagem da praxeologia regional à praxeologia global a teoria e enfatizada.

Chevallard (1998) chama a atenção de que o tipo de tarefa pode não estar bem identificado, assim como a técnica associada pode se revelar impraticável, a tecnologia pode, por vezes, ser reduzida a uma pura declaração de princípios e a teoria, pode ser incompreensível. Ou seja, a teoria pode não estar explicitada, assim como a tecnologia, a técnica...

O funcionamento praxeológico computação de determinada instituição precisará passar pela etapa de avaliação. Momento de reflexão sobre as ações tomadas às organizações praxeológicas (CHEVALLARD, 1998).

Como uma das etapas essenciais para qualquer instituição é a etapa de avaliação de uma organização praxeológica. Segundo Chevallard (1998), avaliar é sempre um processo relativo. Ele parte da argumentação de que o processo de avaliação sempre se refere a um determinado uso social, ou seja, parte de pontos de vistas. Mas para tal, é preciso definir critérios explícitos para esclarecer e justificar, para se ter uma noção de como está organizado a praxeologia (computação).

Chevallard (1998, p.25) mostra alguns critérios de avaliação praxeológica, baseado em questionamentos: critério de identificação, critério de razão de ser, critério de relevância, entre outros. Exemplo:

- Critério de identificação: os tipos de tarefas Ti estão claramente expostos e bem identificados? As tarefas são familiares à instituição?; 
- Critério de razão de ser: as razões para os tipos de tarefas Ti são explicados? Estas tarefas possuem poucos exemplos representados? As técnicas propostas são realmente desenvolvidas ou apenas esboçadas?;

- Critério de relevância: as técnicas são conhecidas pela instituição e são fáceis de utilizá-las? As justificativas explicativas são elas favorecidas? As justificativas são adaptadas às condições da instituição?

\section{Procedimentos metodológicos}

Identificamos a existência de estudo de números binários em livro didático de ciência da computação para o ensino fundamental: "Ensinando ciência da computação sem o uso do computador" (BELL et al, 2011).

Realizamos o seguinte procedimento de análise:

- Selecionamos os capítulos e/ou seções destinados aos números binários;

- Lemos os capítulos e/ou seções selecionados;

- Analisamos a organização praxeológica computação referente ao estudo de números binários, composta por: identificação de tipos de tarefas, técnicas, tecnologias e teorias;

- Caracterizamos o livro didático por meio de organizações praxeológicas: pontuais ou locais ou regionais ou globais;

- Analisamos as praxeologias computação e didática a partir dos critérios de avaliação praxeológica: razão de ser, relevância, identificação de tarefas e técnicas engajadas (prático-técnico), justificativa, explicação da veracidade de técnicas (tecnológico-teórico), representatividade e relação com outras áreas de saber.

\section{Informações a respeito da obra}

O livro analisado objetiva ensinar fundamentos de ciência da computação sem a necessidade de utilização de computadores porque "na realidade, por vezes, o computador torna-se apenas uma distração no processo de aprendizagem" (BELL et al, 2011, p.ii). Este método de ensino é justificado por não necessitar de recursos como hardware e software. É acordado que o livro pode ser ministrado por pessoas que não são especialistas em computação.

Esse livro possui sugestões didáticas para os docentes e atividades para os discentes por "Folha de Atividade".

O livro está estruturado por três partes: "Representando as informações"; "Algoritmos" e "Representando procedimentos". Iremos focar na primeira parte, uma vez que apresentam atividades que ilustram formas utilizadas pelos computadores na representação de dados - relação com os números binários. Essas atividades estão organizadas por tópicos: números binários, representação de imagens, compressão de texto, detecção e correção de erros e Teoria da Informação.

O público alvo deste livro são crianças de diversas idades. Enquanto o nível de escolaridade, destina-se a programas de extensão, aprimoramento, ou educação básica. É enfatizado uma vez que "muito das atividades são baseadas em contextos 
matemáticos como, por exemplo, o entendimento de números binários, uso de mapas e grafos, problemas envolvendo padrões e ordenamento, e criptografia" (BELL et al, 2011, p.ii).

\section{Análise praxeológica computação do livro referente ao estudo de números binários}

O livro não é organizado por questões enumeradas, mas é organizado apenas por perguntas, dentro de determinada seção, sem algum tipo de identificação.

Identificamos 20 tipos de tarefas: T1, T2, T3, T4, T6, T7, T8, T9, T10, T11, T12, T13, T14, T15, T16, T17, T18, T19 e T20. (Vide o Quadro 1). 
Tabela 1 - Tipos de tarefas referentes ao estudo de números binários

\begin{tabular}{|c|c|c|c|}
\hline $\begin{array}{l}\text { Tipos de } \\
\text { Tarefas }\end{array}$ & Descrição & Páginas & Exemplo \\
\hline $\mathrm{T}_{1}$ & $\begin{array}{l}\text { converter um número representado } \\
\text { no sistema decimal em um número } \\
\text { representado no sistema binário }\end{array}$ & 4 e 7 & $\begin{array}{l}\text { Em qual dia do mês você nasceu? Escreva-o em } \\
\text { formato binário (p.7). }\end{array}$ \\
\hline $\mathrm{T}_{2}$ & $\begin{array}{l}\text { converter um número representado } \\
\text { no sistema binário em um número } \\
\text { representado no sistema decimal. }\end{array}$ & $\begin{array}{l}4,7,8,9 \\
\text { e } 10\end{array}$ & $\begin{array}{l}\text { Você pode descobrir o número representado por } \\
10101 \text { ? (p.7). }\end{array}$ \\
\hline $\mathrm{T}_{3}$ & identificar padrões ou sequências & $\begin{array}{c}4,10 \text { e } \\
11\end{array}$ & $\begin{array}{l}\text { o que você percebeu sobre o número de pontos } \\
\text { nos cartões? (p.4). }\end{array}$ \\
\hline $\mathrm{T}_{4}$ & $\begin{array}{l}\text { representar um número natural } \\
\text { como composição de potências de } \\
\text { base } 2 .\end{array}$ & 5 e 7 & $\begin{array}{l}\text { usando um conjunto de varas de comprimento } \\
1,2,4,8 \text { e } 16 \text { centímetros, mostre como é } \\
\text { possível medir qualquer objeto de até } 31 \\
\text { centímetros (p.7). }\end{array}$ \\
\hline$T_{5}$ & $\begin{array}{l}\text { criar uma técnica que possibilite } \\
\text { formar qualquer número natural } \\
\text { como composição de potências de } \\
\text { base } 2\end{array}$ & 5 e 10 & $\begin{array}{l}\text { qual regra você pode seguir para fazer seus } \\
\text { novos cartões (p.10). }\end{array}$ \\
\hline $\mathrm{T}_{6}$ & calcular expressões numéricas & 10 & $\begin{array}{l}\text { Calcule } 1+2+4=\text { ? Qual é o resultado? } \\
\text { Agora, soma } 1+2+4+8=\text { ? }(\text { p.10). }\end{array}$ \\
\hline $\mathrm{T}_{7}$ & $\begin{array}{l}\text { contar, por meio do sistema } \\
\text { binário, utilizando os dedos das } \\
\text { mãos }\end{array}$ & 10 & $\begin{array}{l}\text { Tente contar sequencialmente utilizando seus } \\
\text { dedos. Se o dedo estiver para cima, é um, e, se } \\
\text { estiver para baixo, é zero (p.10) }\end{array}$ \\
\hline $\mathrm{T}_{8}$ & $\begin{array}{l}\text { explicar elementos conceituais de } \\
\text { sistema de numeração binário }\end{array}$ & 11 & $\begin{array}{l}\text { Mas o que acontece quando você coloca um } 0 \text { à } \\
\text { direita de um número binário? (p.11). }\end{array}$ \\
\hline $\mathrm{T}_{9}$ & $\begin{array}{l}\text { calcular a quantidade de bits } \\
\text { necessários para armazenar } \\
\text { caracteres em um computador }\end{array}$ & 11 & $\begin{array}{l}\text { Então, quantos bits são necessários para um } \\
\text { computador armazenar todos os caracteres } \\
\text { (p.11). }\end{array}$ \\
\hline $\mathrm{T}_{10}$ & $\begin{array}{l}\text { desenhar imagens a partir da } \\
\text { decodificação de números de } \\
\text { código }\end{array}$ & 17 & $\begin{array}{l}\text { [...]procure usar lápis para colorir e uma } \\
\text { borracha! (p.17). }\end{array}$ \\
\hline $\mathrm{T}_{11}$ & $\begin{array}{l}\text { desenhar imagens a partir ou } \\
\text { decorrentes da criação de números } \\
\text { de código }^{1}\end{array}$ & 18 e 19 & $\begin{array}{l}\text { Agora que você sabe como os números podem } \\
\text { representar imagens, por que não tentar fazer a } \\
\text { sua própria imagem codificada para um amigo? } \\
\text { (p.18). }\end{array}$ \\
\hline
\end{tabular}

${ }^{1} \mathrm{O}$ tipo de tarefa $\mathrm{T}_{11}$ é parecido com o tipo de tarefa $T_{10}$, decidimos distingui-la pelo fato de que o tipo de tarefa $T_{11}$ solicita a criação de números de código enquanto que o tipo de tarefa $\mathrm{T}_{10}$ já apresenta números de código pré-definido. 
Tabela 1 - Tipos de tarefas referentes ao estudo de números binários (Continuação)

\begin{tabular}{|c|c|c|c|}
\hline $\begin{array}{l}\text { Tipos de } \\
\text { Tarefas }\end{array}$ & Descrição & Páginas & Exemplo \\
\hline $\mathrm{T}_{12}$ & $\begin{array}{l}\text { descomprimir texto - preencher } \\
\text { as letras ou palavras que faltam } \\
\text { nos retângulos guiados por } \\
\text { setas }\end{array}$ & 26 & $\begin{array}{l}\text { [...] Você pode preencher as letras e } \\
\text { palavras que faltam para completá-lo } \\
\text { corretamente? Você as encontrará nos } \\
\text { retângulos apontados pela seta (p.26). }\end{array}$ \\
\hline $\mathrm{T}_{13}$ & $\begin{array}{l}\text { comprimir texto - escolher um } \\
\text { poema ou versinho e } \\
\text { comprimi-lo }\end{array}$ & 26 & $\begin{array}{l}\text { Agora escolha um poema ou versinho } \\
\text { infantil e construa o seu próprio enigma } \\
\text { (p.26) }\end{array}$ \\
\hline $\mathrm{T}_{14}$ & $\begin{array}{l}\text { contar quantas letras existem } \\
\text { em um texto comprimido }\end{array}$ & 28 e 29 & $\begin{array}{l}\text { Quantas letras você consegue marcar } \\
\text { para compressão na história do Três } \\
\text { Porquinhos? (p.29) }\end{array}$ \\
\hline $\mathrm{T}_{15}$ & $\begin{array}{l}\text { detectar e corrigir erros de } \\
\text { códigos }\end{array}$ & $\begin{array}{l}32,33 \\
34 \text { e } 35\end{array}$ & $\begin{array}{l}\text { Pesquise e verifique códigos reais de } \\
\text { ISBN em sua sala de aula ou na biblioteca } \\
\text { (p.35). }\end{array}$ \\
\hline $\mathrm{T}_{16}$ & $\begin{array}{l}\text { analisar a técnica de detecção e } \\
\text { correção de erros de códigos }\end{array}$ & 33 e 35 & $\begin{array}{l}\text { O que acontece quando duas ou mais } \\
\text { cartas são viradas (p.33) } \\
\text { Neste exercício de cartas empregamos a } \\
\text { paridade par - usando um número par } \\
\text { de cartas coloridas. Podemos fazê-lo com } \\
\text { a paridade impar? (p.33). }\end{array}$ \\
\hline $\mathrm{T}_{17}$ & $\begin{array}{l}\text { determinar quais são as } \\
\text { decisões/escolhas da forma } \\
\text { sim/não necessárias para } \\
\text { encontrar algo }\end{array}$ & 39 e 40 & $\begin{array}{l}\text { Quais são as decisões/escolhas da forma } \\
\text { sim/não necessárias para 'adivinhar' o } \\
\text { número } 5 \text { ? (p.40). }\end{array}$ \\
\hline $\mathrm{T}_{18}$ & $\begin{array}{l}\text { determinar quantas } \\
\text { decisões/escolhas da forma } \\
\text { sim/não você deve recorrer } \\
\text { para descobrir algo }\end{array}$ & 39 e 40 & $\begin{array}{l}\text { Quantas decisões/escolhas da forma } \\
\text { sim/não você deve tomar para descobrir } \\
\text { um número qualquer? (p.40). }\end{array}$ \\
\hline $\mathrm{T}_{19}$ & $\begin{array}{l}\text { construir uma árvore de } \\
\text { decisão para descobrir a idade } \\
\text { de alguém }\end{array}$ & 40 & $\begin{array}{l}\text { Qual tipo de árvore você usaria para } \\
\text { adivinhar a idade de alguém? (p.40). }\end{array}$ \\
\hline $\mathrm{T}_{20}$ & $\begin{array}{l}\text { elaborar um jogo de } \\
\text { adivinhação }\end{array}$ & 39 & $\begin{array}{l}\text { Faça um jogo de adivinhação com uma } \\
\text { frase curta de } 4 \text { a } 6 \text { palavras (p.39). }\end{array}$ \\
\hline
\end{tabular}

Identificamos 7 técnicas: 1, 2, 3, 4, 5 , 6 e , 7 .

A técnica 1 , situada na página 4 , pode ser utilizada para resolver os tipos de tarefas T1, T2 e T4. Ela é principalmente utilizada para converter números representados no sistema binário em um número representado no sistema decimal. Tanto a atividade que utiliza 5 cartões marcados por pontos, página 5 , como a atividade que utiliza lâmpadas, página 8 , como a atividade que utiliza códigos: bip e bop, página 9, e como a atividade que utiliza os dedos da mão para contar por meio do sistema binário, página 10 , são resolvidas pela técnica 1 . Esta técnica parte do seguinte procedimento:

Primeiro, corresponder os dígitos binários, 1 e 0 , às duas situações dicotômicas ou símbolos opostos (Momento de representação dos códigos, sinais como dígitos binários). Exemplos: corresponder o lado do cartão que contém pontos ao dígito 1 binário (face para cima) e corresponder o lado do cartão que 
não contém pontos ao dígito 0 binário (face para baixo); Corresponder a lâmpada de árvore de Natal acessa ao dígito 1 binário e corresponder esta lâmpada apagada ao dígito 0 binário; Corresponder o "Bip" ao dígito 1 binário e corresponder o "Bop" ao dígito 0 binário; Corresponder o dígito 1 binário ao dedo da mão levantado e corresponder o dígito 0 binário ao dedo da mão abaixado.

Segundo, recorrer aos cartões pontuados, Figura 1 e Figura 2, contendo quantidades em potências de base 2, a partir de 1, em um lado do cartão e do outro lado não contendo nenhum ponto (vazio) (Momento de converter o número representado no sistema binário em um número representado no sistema decimal).

Terceiro, colocar os cartões da direita para a esquerda conforme a ordem crescente das potências de $2: 1,2,4,8,16 \ldots$ pontos;

Quarto, pôr todos os cartões com a face para baixo;

Quinto, como cada cartão é um dígito binário, 1 bit, virar para cima os cartões que correspondem ao digito 1 binário;

Último, adicionar os pontos de cada cartão. O total será o número, convertido para o sistema de numeração decimal, procurado.

Figura 1 - 5 Cartões contendo 1, 2, 4, 8 e 16 pontos

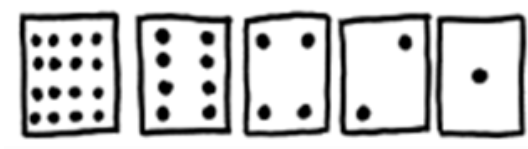

(Fonte: BELL et al, 2011, p.4)

Figura 2 - Técnica adotada para converter um número representado no sistema decimal em um número representado no sistema binário (vice-versa)

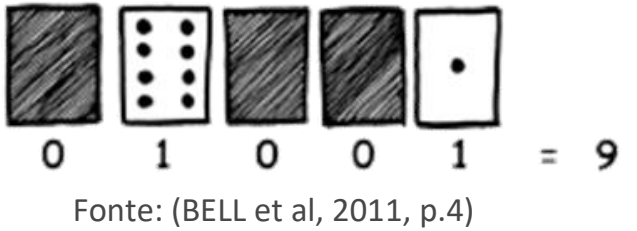

A técnica 2, situada na página 15, pode ser utilizada para resolver os tipos de tarefas T10 e T11. Ela é utilizada para codificar/decodificar imagens, preta e branca. Esta técnica parte do seguinte procedimento:

Primeiro, um pixel branco corresponde ao dígito 0 binário e um pixel preto corresponde ao dígito 1 binário;

Segundo, o primeiro número do código sempre se refere ao número de pixels brancos;

Terceiro, se o primeiro pixel for preto, então a primeira linha de números do código será igual a zero;

Quarto, os números de códigos sempre são correspondentes, gerados linha por linha da tabela e escritos da esquerda para a direita. 
A técnica 3, situada na página 19, pode ser utilizada para resolver o tipo de tarefa T11. Ela é utilizada para codificar/decodificar imagens coloridas. Esta técnica parte do seguinte procedimento:

Primeiro, corresponder um número natural a alguma cor;

Segundo, cada grupo de pixel será representado por 2 números tal que o primeiro número representará a quantidade de pixels do conjunto ou células da tabela e o segundo número representará o tipo de cor;

Terceiro, os números de códigos, dois a dois, sempre são correspondentes, gerados linha por linha da tabela e escritos da esquerda para a direita.

A técnica 4 , situada nas páginas 24 e 27 , pode ser utilizada para resolver os tipos de tarefas T12, T13 e T14. Ela é uma técnica de compressão de textos que parte inicialmente da identificação de padrões para que daí seja representada por uma forma de codificação de dados. Esta técnica parte do seguinte procedimento:

Primeiro, identificar no texto grupos de duas ou mais letras ou palavras que se repetem;

Segundo, substituir esses padrões, grupos de duas ou mais letras ou palavras repetidas, por representação de um retângulo em branco;

Terceiro, inserir setas que apontem para uma parte anterior do texto, ou seja, inserir setas que apontem a partir da representação de um retângulo em branco até os grupos de pelo menos duas letras ou palavras originais;

Quarto, representar as palavras que possuem letras repetidas por meio de dois números, tal que o primeiro número indica a posição anterior que o computador deverá iniciar a cópia das letras e o segundo número indica o número de cópia de letras consecutivas;

Quinto, ler o texto comprimido no sentido da esquerda para a direita e de cima para baixo.

A técnica 5, situada nas páginas 32 e 33, pode ser utilizada para resolver o tipo de tarefa T15. Ela é uma técnica de detecção e correção de erros de códigos. Esta técnica parte do seguinte procedimento:

Primeiro, escolher uma criança para que ela construa uma tabela contendo 5 x 5 cartões coloridos com a mesma cor em um dos lados;

Segundo, adicionar mais uma linha abaixo da tabela e uma coluna a direita da tabela $5 \times 5$, de maneira que tenham 36 cartões no total e que obedeçam a seguinte regra: se os número de cartões coloridos de cada linha e de cada coluna (da 1a a 5 a célula, respectivamente, da esquerda para a direita e de cima para baixo) for impar, então a 6ㅇ cartão será colorido. Se não (se for par), então a 6 cartão não será colorido;

Terceiro, solicitar que uma criança vire um cartão enquanto você cobre seus olhos;

Quarto, indicar qual é a linha e a coluna alterada;

Quinto, indicar qual é o cartão virado pela criança.

A técnica 6 , situada na página 34 , pode ser utilizada para resolver o tipo de tarefa T16. Ela é uma técnica de detecção e correção de erros de códigos (de 
barras) de livros. Chamada de ISBN - International Standard Book Number. Esta técnica parte do seguinte procedimento:

Primeiro, multiplicar: o 10 dígito por 10, o 2ㅇ dígito por 9, o 3으 dígito por 8,0 4ㅇ dígito por 7,0 50 dígito por 6,0 6음 dígito por 5,0 70 dígito por 4,0 8 dígito por 3,0 9o dígito por 2 e o 10 ㅇ́ㅁito por 1 ;

Segundo, somar todos os produtos;

Terceiro, dividir o total por 11;

Quarto, verificar se o resto da divisão é igual ao o último dígito do código. Se o resto da divisão for igual a 10, então o valor 10 corresponderá a letra X; Se o resto da divisão for igual ao último dígito do ISBN, então o código está correto. Se o resto da divisão for diferente ao último dígito do ISBN, então o código está errado.

A técnica 7, situada nas páginas 39 e 40, pode ser utilizada para resolver os tipos de tarefas T17, T18 e T19. Ela é uma técnica para medir a informação que recorre de um método de fazer perguntas por meio de relações (maior que, menor que), de inclusão/exclusão de padrões (É uma vogal? É uma ave?) tomando-se, apenas, como resposta sim ou não. Esta técnica parte do seguinte procedimento:

Primeiro, formular uma pergunta que contenha, estritamente, como resposta, "sim" ou "não"; formular perguntas por meio de relações (maior que, menor que) ou de inclusão/exclusão de padrões;

Segundo, contar quantas perguntas, decisões/ escolhas da forma sim/não, foram feitas;

Terceiro, a quantidade de perguntas feitas é o valor da medida da informação.

A técnica 1 é justificada. Identificamos, então, a tecnologia 1 pela seguinte interpretação: baseado no conceito de sistema de numeração de base 2 ou sistema binário presente no livro, o dígito binário, o bit, pode assumir, apenas, dois valores ou símbolos distintos: 1 ou 0 . O cartão representa 1 bit: o lado do cartão que conter pontos corresponde a 1 e lado do cartão que não conter pontos corresponde a 0 . Organizando os cartões da direita para a esquerda conforme a ordem crescente da quantidade de pontos em potências de base 2 , a partir de 1 , configura-se dessa maneira, as ordens numéricas binárias. Define, portanto, o sistema de numeração binário. 01 을 cartão contém 1 ponto, o $2^{\circ}$ cartão (lado esquerdo do 1ํ) contém 2 pontos, o 3 ㅇ cartão (lado esquerdo do 2ㅇ) contém 4 pontos, o 4 ㅇ cartão (lado esquerdo do $3^{\circ}$ ) contém 8 pontos e assim sucessivamente (Figura 1 e Figura 2). Ou seja, a 1aㅡ 2aㅡ, 3aㅡ, n-ésima ordem numérica binária mantém correspondência ao 1 은 cartão, ao 2 을 cartão, ao 3 ํ cartão, ao n-ésimo cartão. Além disso, "todos os locais [ordens] contendo ' 1 ' valem agora duas vezes seu valor anterior, e assim o número total é duplicado. ( $N a$ base 10, acrescentando um zero à direita do número multiplica-o por 10)" (BELL et al, 2011, p.13). Ou seja, "quando você coloca um zero à direita de um número binário, esse número é dobrado" (ibidem).

As técnicas 2 e 3 caracterizam-se como técnicas de compressão de imagens; são justificadas, mas não explicadas: "se as imagens não fossem comprimidas, estas levariam muito mais tempo para serem transmitidas e exigiriam muito mais espaço para armazenamento. Isto tornaria inviável enviar páginas de fax ou colocar fotos em uma página da Internet" (BELL et al, 2011, p.21). Portanto, existem 
página é afirmado que uma máquina de fax realiza uma varredura sobre uma página em preto e branco, armazena-a em, aproximadamente, $1000 \times 2000$ pixels, e que estes pixels são posteriormente transmitidos a uma outra máquina de fax através de um modem. No entanto, não é explicado como é feita esta varredura e nem como o fax envia os pixels para outro fax. Portanto, inexistem teorias que fundamentem essas justificativas.

A técnica 4 caracteriza-se como uma técnica de compressão/decompressão de textos chamada de codificação Ziv-Lempel ou codificação ZL. Ela é justificada, mas não apresenta embasamento teórico. Justifica que devido ao crescimento de cerca de um milhão de vezes a capacidade de armazenamento de dados nos últimos 25 anos, necessita-se diminuir a quantidade de armazenamento de dados e aumentar a sua velocidade de transmissão via modem ou via computador por meio de codificação/decodificação de dados para o processo de compressão de dados. Na página 27 , explica que "às vezes, textos incompletos apontam para parte dele mesmo. Neste caso, o texto pode ser decodificado corretamente se as letras forem copiadas da esquerda para a direita [...] Em computadores as caixas e flechas são representadas por números [binários]" (BELL et al, 2011, p.27). A técnica 4 recebe, portanto, elementos tecnológicos imbricados (tecnologia 3) na sua própria execução. Enfatizamos o fato de que as caixas e as flechas são representadas por números binários, o que explica como os computadores "traduzem" o quarto e o quinto procedimento da técnica 4 .

As técnicas 5 e 6 configuram-se como técnicas de deteç̧ão/correção de erros de dados por computadores. A linha e a coluna acrescida no procedimento realizado na técnica 5 , bits de paridade, e o décimo dígito recorrido no procedimento realizado na técnica 6 configuram-se como dígitos verificadores de erros de dados. Ou seja, "a mesma técnica que foi utilizada no jogo de 'virar as cartas' é usada em computadores" (BELL et al, 2011, p.36), seja para verificar se os dados recebidos foram corrompidos por algum tipo de interferência, ruído na transmissão, por exemplo. É chamada a atenção de que

[...] os computadores usam frequentemente sistemas de controle de erros mais complexos capazes de detectar e corrigir erros múltiplos. $\mathrm{O}$ disco rígido em um computador tem uma grande quantidade de espaço alocado para corrigir erros para que este funcione de forma confiável ainda que partes do disco falhem. Os sistemas utilizados para esse fim são bastante próximos ao esquema de paridade (BELL et al, 2011, p.36).

Constatamos que os bits de paridade e o décimo dígito utilizado no ISBN configuram-se tanto como elemento constituinte da técnica (tarefas concluintes dos procedimentos) como também da tecnologia (explicam a sua veracidade). Portanto, as técnicas 5 e 6 recebem elementos tecnológicos. Notaremos como tecnologia 4.

A técnica 7 é justificada e explicada. Chamaremos de tecnologia 5. A quantidade de informação contida nas mensagens é mensurada pela dificuldade em descobri-las. A quantidade de perguntas configura-se no valor da quantidade de informação. De modo que as respostas sejam estritamente sim ou não. Por essa consideração, corresponde à resposta sim ao dígito 1 binário e corresponde à resposta não ao dígito 0 binário (vice-versa). A determinação da quantidade de decisões/escolhas tomadas da forma sim/não possibilita descobrir algo pretendido (um número, uma letra, uma palavra, etc.) de forma que a sequência de respostas, 
sim/não, seja representada por uma sequência de dígitos binários, o que irá indicar o código binário do algo pretendido. A árvore de decisão, Figura 3, é uma representação das decisões/escolhas da forma sim/não por números binários.

A técnica 7 é empregada por estratégia ótima, levando-se em consideração, apenas, respostas sim ou não, tomando-se a sequência em ordem numérica crescente/decrescente.

A técnica 7 recebe complementação tecnológico-teórico ao citar Claude Shannon como descobridor desse jogo, dessa técnica de medir informação chamada de entropia, que toma cada resposta sim/não equivalente a um bit 1/0, de tal maneira que a entropia de uma mensagem dependa não apenas do número de resultados possíveis, mas também da sua probabilidade de ocorrência.

Shannon chamou as informações relativas aos conteúdos de uma mensagem de 'entropia'. A entropia depende não apenas do número de resultados possíveis - dois, no caso do lançamento de uma moeda - mas também na probabilidade disso acontecer. Acontecimentos improváveis ou informações surpreendentes requerem mais perguntas para adivinhar a mensagem porque estes nos fornecem mais informações além das quais já sabíamos, como no caso de ir em um helicóptero para a escola (BELL et al, 2011, p.41).

Além disso, de maneira indireta, afirma que a entropia é o mínimo de bits necessários para mensurar uma informação no seguinte trecho: "Você não pode comprimir uma mensagem de tal forma que esta ocupe menos espaço do que sua entropia [...]" (BELL et al, 2011, p.41). Ou seja, a entropia é a melhor opção possível de perguntas feitas.

Figura 3 - Árvore de decisão - "Folha da Atividade: Árvores de Decisão". Se você já sabe a estratégia para fazer as perguntas, você pode transmitir uma mensagem sem ter que perguntar nada.

\section{A seguir temos um esquema chamado de "árvore de decisăo" que permite adivinhar um número entre 0 e 7 :}

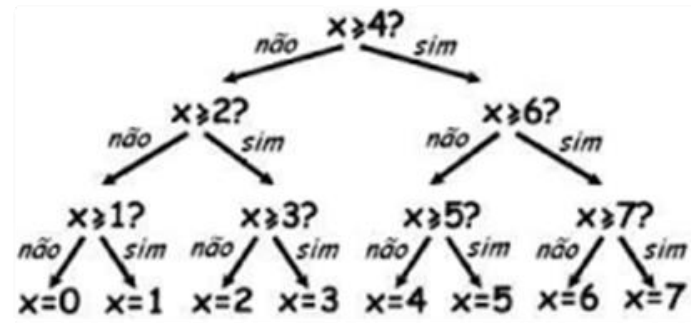

(Fonte: BELL, et al, 2011, p.40)

Critérios de avaliação praxeológica didática e praxeológica computação referentes ao estudo de números binários

Critério de identificação: considerando a abordagem do estudo de números binários ser destinada a crianças, o seu nível de aprofundamento é satisfatório. Existe a elaboração de tarefas atreladas à exercitação de técnicas e algumas delas são justificadas e fundamentadas teoricamente. Identificamos 20 tipos de tarefas. A subtarefa mais presente é representar dados por dígitos binários. A maioria das tarefas tem cunho didático, direcionam a execução de determinada etapa da técnica, como exemplo: "Quais são as decisões/escolhas da forma sim/não 
necessárias para 'adivinhar' o número 5 ? Quantas decisões da forma sim/não deve tomar para descobrir um número qualquer?" (BELL et al, 2011, p.40).

Critério de razão de ser: os elementos praxeológicos giram em torno de dois questionamentos: como armazenar informações nos computadores? Como números, palavras e imagens podem ser representados por dígitos binários? A partir disso, são trabalhadas técnicas de representação de imagens, números e palavras usando apenas dois dígitos binários, 0 e 1; técnicas de compressão de dados (textos e imagens); técnica de medição de informação; técnicas de codificação e de deteç̧ão e correção de erros. Portanto, por um contexto computacional, os números binários são estudos porque "os computadores atualmente utilizam o sistema binário para representar informações" (BELL et al, 2011, p.12); porque são utilizados para representar dados via armazenamento, transmissão, compressão, codificação, detecção e correção de erros.

Critério prático-técnico: na página 7, representa os algarismos binários por meio de outros símbolos (códigos), disso, solicita que a aluna e o aluno decifrem os códigos conforme a Figura 4. Busca converter números representados por diferentes tipos de símbolos em números representados nos sistema de numeração binário. Ao nosso ver, não fica claro o objetivo de se adotar outros símbolos diferentes de 0 e de 1 para representar números no sistema binário. Ao invés de definir cada símbolo pelo seu correspondente, 0 ou 1, ficaria a critério de sua escolha aos próprios alunos e alunas identificarem uma relação possivelmente existente entre os símbolos $\nabla \mathbf{\nabla} \$ \mathbf{X}$ e os dígitos binários. Além disso, não existe orientação ao docente a respeito de que tanto os símbolos 0 e 1 ou qualquer um daqueles tomados como opostos, podem compor a representação de um número no sistema de numeração binário.

Figura 4 - Tarefa da página 7: decifrando códigos

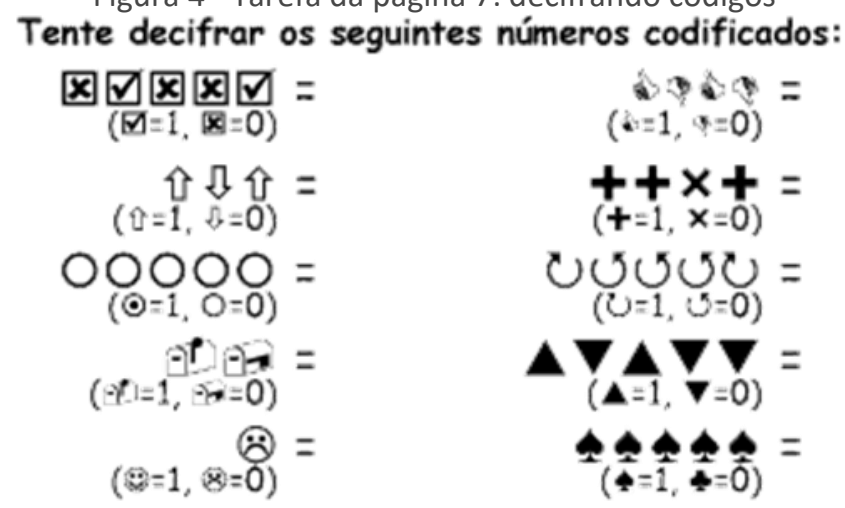

(Fonte: BELL et al, 2011, p.7)

A técnica de conversão de um número representado no sistema de numeração binário em um número representado no sistema de numeração decimal é clara e interessante, uma vez que recorre de uma atividade lúdica, manipulável, por meio de cartões. Embora, a técnica de conversão de um número representado no sistema de numeração decimal em um número representado no sistema de numeração binário não seja ilustrada no livro. Porém, ela é solicitada por meio de uma tarefa: "Tente formar os números 1, 2, 4, nessa ordem. Depois disso, você consegue descobrir um método de virar as cartas que permitem formar qualquer número?" (BELL et al, 2011 p.5). O que é interessante uma vez que estimula o 
raciocínio matemático em criar mecanismos pertinentes a resolução de problemas.

Na "Atividade 2" são estudadas duas técnicas, 2 e 3, como exemplo de codificação/decodificação de imagens (preta e branca, e colorida). Está bem clara, tanto a proposta de ensino, representar imagens armazenadas em computadores por meio de números (naturais), quanto a execução das técnicas. Elas são trabalhadas por atividades lúdicas (pinturas em tabelas e desenhos), o que pode motivar e fomentar a aprendizagem de crianças a partir de 7 anos (idade recomendada). São sugeridas orientações referente a execução das tarefas, o que pode auxiliar a sua execução. Como exemplo:

Tente desenhar com uma folha de papel sobre a grade, de modo que a imagem final possa ser vista sem a grade. A imagem será mais clara. Ao invés de colorir a grade, as crianças podem utilizar quadrados de papel colante ou colocar objetos em uma grade maior (BELL et al, 2011, p.20)

A técnica 4 é apresentada por etapas, o que são didaticamente aconselhadas, desde a identificação de padrões nos textos, letras ou palavras repetidas, até a criação de um código numérico para representar estes padrões, assim como visto aqui na descrição de seu procedimento. Estas etapas são orientadas por subtarefas ou dicas, como exemplo: "Você consegue encontrar grupos de duas ou mais letras repetidas, ou mesmo palavras ou frase inteiras?" (BELL et al, 2011, p.24); "Certifique-se de que as setas apontem sempre para uma parte anterior do texto" (BELL et al, p.26); "Tente evitar o uso demasiado de setas. Deixe bastante espaço livre em volta das letras e palavras ao escrever de modo que você tenha espaço para os retângulos e as setas que apontam para estes" (BELL et al, 2011, p.26). Dessa forma, as tarefas e subtarefas são atreladas à técnica que de certa maneira norteia a sua execução.

As técnicas 5 e 6 são ilustradas e posteriormente são exercitadas por tarefas em forma de perguntas sem algum tipo de identificação. São elaboras tarefas e subtarefas de suporte e/ou aprofundamento da técnica, o que de certa maneira pode auxiliar na compreensão do estudo apresentado. Exemplo de perguntas de suporte: "Quantas cartas coloridas estão em cada linha e coluna? Trata-se de um número par ou impar?" (BELL et al, 2011, p.33). Exemplo de perguntas de aprofundamento: "o que acontece quando duas ou mais cartas são viradas?" (BELL et al, 2011, p.33). "Você pode alterar um dígito e ainda obter a soma verificadora correta?" (BELL et al, 2011, p.35).

A "Atividade 5" não evidencia que a técnica 7 é empregada por estratégia ótima, por considerar, apenas, respostas sim ou não, tomando-se a sequência em ordem alfabética ou numérica. Ou seja, a técnica adotada para medir informação, a partir da descoberta de um número, por meio de elaboração de perguntas contendo sim ou não como respostas, inserido em um intervalo de números, não enfatiza a necessidade de números estarem em ordem crescente ou decrescente no intervalo, o que seria uma condição para tal método. É mostrada uma "árvore de decisão", na página 40 (Vide Figura 3), como uma representação visual da técnica de medir informação. O que é interessante pelo fato de evidenciar a representação dos números como códigos binários. Dessa maneira, articula a proposta de mostrar uma técnica para medir informação conjunta com o estudo de números binários, vista na Atividade 1, assim como exposto abaixo: 
Agora veja algo extremamente fascinante. Abaixo dos números $0,1,2,3, \ldots$, na última linha da árvore, escreva em binário (veja a Atividade 1).

Olhe cuidadosamente para a árvore. Se não $=0$ e $\operatorname{sim}=1$, o que você nota?

No jogo de adivinhar números, procuramos escolher as perguntas de tal forma que a sequência de respostas sirva para representar o número exatamente dessa maneira (BELL et al, 2011, p.40)

Além disso, articula questionamentos que podem oportunizar a compreensão das alunas e dos alunos sobre a relação existente entre os números binários e cada número do intervalo, sendo este representado por meio de códigos binários. Dessa forma, o conteúdo não é "transferido" para o aluno e para a aluna, mas construído a partir de questionamentos, os alunos e as alunas podem estruturar a sua própria aprendizagem. $O$ contexto da computação é relevante uma vez que pode motivar e estimular a aprendizagem das alunas e dos alunos.

Critério tecnológico-teórico: a justificativa dada para saber a quantidade de bits necessários para representar algum caractere, como exemplo, utilizar apenas 5 cartões, e não 4 ou alguma quantidade menor, para poder escrever números de 0 até 31, ao nosso ver, não é clara: "Um único bit não consegue representar muito. Por isso, os bits são utilizados geralmente em grupos de oito, podendo representar números de 0 a 255. Um grupo de oito bits é chamado de byte" (BELL et al, 2011, p.12, grifo nosso). Não menciona a formação de combinações de códigos (sequência de dígitos binários), como exemplo: 1 bit corresponde apenas a dois símbolos ( $A$ ou $B$ ); 2 bits correspondem a 4 símbolos ( $A B, A A, B A, B B$ ); 3 bits correspondem a 8 símbolos ( $A A A, A A B, A B A, A B B, B A A, B A B, B B A$ e $B B B$ ); e assim por diante. Não recorre da própria técnica por cartões trabalhada para justificar, como por exemplo: expor os cartões da direita para a esquerda em ordem de potência de base 2 e contar os pontos de cada.

$\mathrm{Na}$ "Atividade 2" - "Colorindo com Números", ao nosso ver, faltou retomar a conversão de números de código na abordagem da técnica de compressão de imagens, preta e branca, e colorida, em dígitos binários. O que poderia justificar a varredura feita pelo fax sobre uma folha de papel de forma que o sensor captaria os pixels (pontos brancos ou pretos), digitalizaria linha por linha e enviaria de maneira digital e serial para outro fax. O que poderia responder os seguintes questionamentos: Como o computador, fax irão ler os números após a codificação de imagens? "O que as máquinas de fac-simile (fax) fazem?" (BELL et al, 2011, p.15). Por outro lado, vale considerar que a proposta didática da primeira parte do livro objetivou mostrar como os computadores armazenam imagens usando apenas números por meio de atividades, e não como os "computadores leem" esses números, o que abrangeria um nível maior de profundidade no tema?

$\mathrm{Na}$ "Atividade 3" é apresentada uma técnica de compressão de textos. Achamos interessante a sua abordagem porque apresenta a técnica por partes, desde a substituição de padrões, letras ou palavras repetidas, por retângulos brancos indicados por setas às letras ou palavras originais até a criação de um número de código contendo dois valores, o primeiro indicando a quantidade de casa a ser voltado e o segundo indicando a quantidade de letras a ser copiado. No entanto, não retoma e nem frisa o estudo de números binários como representação de códigos, o que explicaria a leitura dos textos codificados/decodificados pelos modems e computadores em geral. A compressão ou compactação de dados seria melhor justificada após a abordagem de medida 
de informação, última atividade ("Atividade 5") desta parte do livro, porque iria corresponder um caractere a um byte (unidade de medida de informação), e disso, iria medir a quantidade de armazenamento de dados antes e depois do texto ser compactado. No entanto, isto não foi ocorrido, como veremos a seguir.

A "Atividade 5" é a que apresenta maior relação entre os blocos práticotécnico e tecnológico-teórico. Levando-se em consideração o publico alvo, crianças a partir de 10 anos, trabalha noções teóricas de maneira clara e simples, como entropia, que é a quantidade de informação, tal que o número de perguntas é o valor da medida da informação, que por sua vez dependem não apenas do número de resultados possíveis de perguntas, mas também da probabilidade disso acontecer; Contextualiza com elementos da computação, como exemplo ao método utilizado pelos computadores atuais a sugerirem o que será digitado na sequência após digitação do usuário. Além disso, relaciona as respostas sim/não das perguntas aos dígitos binários $1 / 0$, enfatiza de maneira clara e simples que 0 jogo de adivinhar o número - técnica trabalhada - apresentar perguntas escolhidas de determinada maneira, poderá obter sequência de respostas representadas por números binários, assim como ilustrada na "Folha de Atividade: Árvores de Decisão" por meio da árvore de decisão. Mantendo com isso, uma recapitulação à primeira atividade: "Números Binários". No entanto, não aborda as unidades de medida de informação. Dessa forma, não complementa a abordagem de compressão/decompressão abordada na Atividade 3.

$\mathrm{Na}$ abordagem das técnicas 5 e 6, não está clara a relação das cartas e nem do código ISBN com os números binários. Apenas é sugerida a correspondência entre os dígitos binários e os estados dicotômicos: "Tente usar outros objetos. Tudo o que tem dois 'estados' é apropriado. Por exemplo, você poderia utilizar cartas de baralho, moedas (cara ou coroa) ou cartões impressos com 0 ou 1 (para referir-se ao sistema binário)" (BELL et al, 2011, p.33). Na abordagem da técnica 5 , é justificado que a linhas e colunas acrescidas na tabela $5 \times 5$ são bits de paridade, que servem para detectar e corrigir erros, que por sua vez o bit incorreto ou corrompido é modificado. No entanto, esta justificativa não é clara e nem ilustrada apesar de ser afirmado, por escrito, que "a linha e coluna que contém a carta modificada agora terão um número impar de cartas coloridas, e isto identificará a carta modificada" (BELL et al, 2011, p.32). Por exemplo, caso uma criança representasse os cartões conforme a Figura 5, a professora ou o professor iria acrescentar uma linha a baixo e uma coluna a esquerda para representar os bits de paridade conforme a Figura 6. Suponha que a criança tenha virado o cartão da 3a linha, 2a coluna conforme a Figura 7. A professora ou o professor iria mostrar a linha e a coluna corrompida e nessa intersecção da linha e da coluna iria encontrar o bit corrompido ou o cartão virado pela criança conforme a Figura 8. 
Figura 2 - Arrumação dos cartões pelo estudante

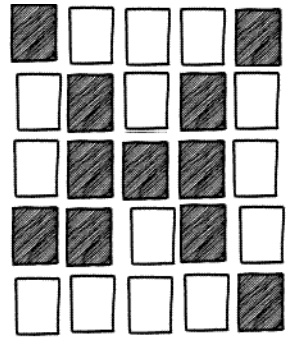

Figura 7 - Cartão virado pelo estudante

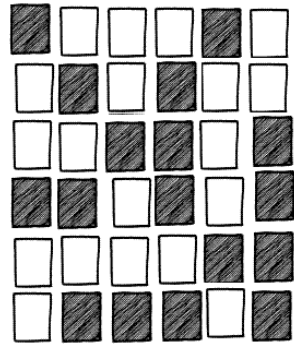

Figura 1 - Acréscimo de uma linha e de uma coluna (bits de paridade) pela professora

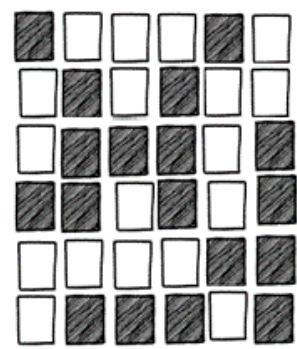

Figura 8 - Identificação da linha, da coluna e do cartão modificado em vermelho.

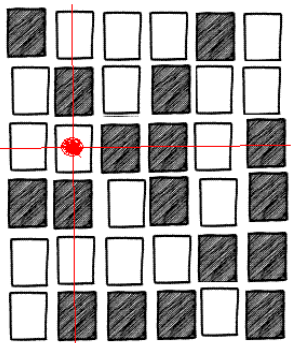

Critério de relevância: os números binários são considerados como tema fundamental em Ciência da Computação. É afirmado que "dados são a matériaprima, os números com os quais os computadores trabalham" (BELL et al, 2011, p.2). E a partir disso, o computador transforma dados em informação. "Os dados são armazenados em computadores e transmitidos como uma série de zeros e uns" (BELL et al, 2011, p.3). Os números binários são utilizados na representação de dados como armazenamento (1), transmissão (2), detecção e correção de erros (3), compressão (4), código (5) e medida de informação (6):

1.“Um bit é normalmente representado na memória principal do computador por um transistor, que pode está ligado ou desligado, ou um capacitor, que pode estar carregado ou descarregado" (BELL et al, 2011, p.12);

2."Quando os dados devem ser transmitidos por uma linha telefônica ou enlace de rádio, tons de alta e baixa frequência são utilizados para os zeros e uns" (BELL et al, 2011, p.12);

3.“Imagine que você está depositando $\mathrm{R} \$ 10,00$ em dinheiro na sua conta bancária. O caixa digita o valor do depósito e o envia para um computador central. Contudo, suponha que alguma interferência ocorreu na linha enquanto o montante está sendo enviado e o código de $\mathrm{R} \$ 10,00$ é alterado para $\mathrm{R} \$ 1.000,00$. Não há problema se você for o cliente, mas obviamente, há claramente um problema para o banco!" É importante detectar erros nos dados transmitidos. Portanto, um computador precisa verificar que os dados recebidos não foram corrompidos por algum tipo de interferência elétrica na linha de transmissão [...] Colocando bits em linha e colunas imaginárias, e acrescentado bits de paridade para cada linha e coluna, podemos não apenas detectar se ocorreu um erro, mas quando este erro aconteceu. O valor do bit incorreto é modificado e, com isso, realizamos sua correção" (BELL et al, 2011, p.36); 
4. "Se as imagens não fossem comprimidas, estas levariam muito mais tempo para serem transmitidas e exigiriam muito mais espaço para armazenamento" (BELL et al, 2011, p.21);

5. "No jogo de adivinhar o número, se as perguntas são escolhidas de certa maneira, a sequência das respostas é simplesmente a representação binária do mesmo. 0 número três é 011 em binário e é representado pela resposta 'Não, sim, sim' na árvore de decisão, o que equivale a escrevermos não para 0 e sim para 1 " (BELL et al, 2011, p.42);

6. "[Calude Shannon] mensurou a quantidade de informação em bits - cada resposta sim/não equivale a um bit $1 / 0^{\prime \prime}$. Ele descobriu que a quantidade de 'informação' contida numa mensagem depende do que você já sabe" (BELL et al, 2011, p.41).

Critério de representatividade: identificamos na primeira parte do livro, total de 42 páginas, 20 tipos de tarefas relacionados aos números binários, distribuído em 17 atividades. Todas elas recorrem aos números binários como maneira de representar dados, seja por meio de sua codificação, compressão, transmissão, armazenamento, etc. As medidas de informação também são trabalhadas, porém as unidades de medidas são omissas. Apenas apresentam o bit e o byte como unidades de medida.

Critério de relação com outras áreas de saberes: na seção, "Números Binários", as atividades podem possibilitar o reconhecimento de ordenação, de padrões ou de sequências numéricas relacionadas com as potências na base 2 (potenciação - conteúdo da matemática básica). Especificamente, temos como exemplo as seguintes tarefas: "O que você percebeu sobre o número de pontos nos cartões?"; "Quantos pontos teria o próximo cartão colocado à esquerda? (32) E o próximo...?" (BELL et al, 2011, p.4). Na execução da tarefa da "Atividade 4" referente a deteç̧ão e correção de erros de números de códigos a partir da técnica 5 , poderá fazer relação com um tema da matemática, coordenadas cartesianas, ao detectar e corrigir o erro (cartão alterado).

\section{Conclusão}

Concluímos que a abordagem de números binários no livro analisado caracteriza-se como sendo uma praxeologia regional: 20 tipos de tarefas, 7 técnicas, 5 tecnologias e 1 princípio de teoria (Vide Quadro 1). Tipos de tarefas são atrelados à exercitação de técnicas. Todas estas recebem elementos tecnológicos. Estes são imbricados na própria execução das técnicas ou justificadas e/ou explicadas, geralmente, em uma seção própria intitulada: "De que se trata tudo isso?"; uma única tecnologia é teorizada (por meio de princípios de teoria da informação e comunicação de Shannon referente à medição de informação); as subtarefas mais presentes são: representar dados por dígitos binários; ordenar números; fazer correlações e contar.

Concluímos que os elementos praxeológicos computação e didático buscam explicar de que forma podemos representar textos e imagens a partir de números binários e de como armazenar dados em computadores. Os números binários são abordados por meio de representação de dados como armazenamento, 
transmissão, detecção/correção de erros, compressão, codificação e medição de informação.

Quadro 1 - Praxeologia Regional

\begin{tabular}{|c|c|c|c|c|}
\hline $\begin{array}{c}\text { Tipos de } \\
\text { Tarefa }\end{array}$ & Páginas & Técnicas & Tecnologias & Teorias \\
\hline $\mathrm{T}_{1}, \mathrm{~T}_{2}, \mathrm{~T}_{4}$ & 4 a 11 & $\tau_{1}$ & $\theta_{1}$ & \multirow{6}{*}{ - } \\
\hline $\mathrm{T}_{10}, \mathrm{~T}_{11}$ & 15 a 18 , e 20 & $\tau_{2}$ & \multirow{2}{*}{$\theta_{2}$} & \\
\hline $\mathrm{T}_{11}$ & 19 & $\tau_{3}$ & & \\
\hline $\mathrm{T}_{12}, \mathrm{~T}_{13}, \mathrm{~T}_{14}$ & 24 a 29 & $\tau_{4}$ & $\theta_{3}$ & \\
\hline $\mathrm{T}_{15}$ & 32 e 33 & $\tau_{5}$ & \multirow{2}{*}{$\theta_{4}$} & \\
\hline $\mathrm{T}_{16}$ & 34 e 35 & $\tau_{6}$ & & \\
\hline $\mathrm{T}_{17}, \mathrm{~T}_{18}, \mathrm{~T}_{19}$ & 38 a 40 & $\tau_{7}$ & $\theta_{5}$ & $\Theta_{1}$ \\
\hline
\end{tabular}




\title{
Praxeologic analysis of a computer science textbook about binary numbers study
}

\begin{abstract}
It aims to analyze the praxeological computing and didactic praxeology organizations of a textbook of computer science at the elementary school level regarding the study of binary numbers. Refers to the Anthropological Theory of the Didactic (ATD) of Yves Chevallard as theoretical framework and more specifically, one of his concepts, praxeology, as a methodological tool for research. From the definition of research problems, are these types of tasks for the study of binary numbers are clearly stated and well identified? Are the techniques related to these tasks illustrated, justified, and theorized? It concludes that the approach of binary numbers is characterized as regional praxeology. It identifies 20 types of tasks, 7 techniques, 5 technologies and 1 principle of a theory (theory of Shannon information and communication).
\end{abstract}

KEYWORDS: Binary Numbers. Praxeology. Computer science textbook. 


\section{REFERÊNCIAS}

BELL, Tim et al. Computer Science Unplugged: ensinando computação sem o uso do computador: Trad: Luciano Porto Barreto.csunplugged.org, 2011.

BOSCH, Marianna; GASCÓN, Josep. 25 años de Transposición Didáctica. In L. RuizHigueras, A. Estepa, F. J. García (Eds.) Sociedad, Escuela y Matemáticas. Aportaciones de la Teoría Antropológica de lo Didáctico. Jaén: Publicaciones de la Universidad de Jaén, 2007. p. 385-406.

CHEVALLARD, Yves. Analyse des pratiques enseignates et didactique des mathematiques: I'approche anthropologique, 1998. Disponível em <yves.chevallard.free.fr> Acesso em abril 2014.

CHEVALLARD, Yves. Steps towards a new epistemology in Mathematics Education In 4 ㅇ Congrés de la European Society for research in mathematics education (CERME 4), France, 2005. Disponível em: <Yves.chevallard.free.fr> Acesso em nov. 2014

MENDES, Herman do Lago. Análise praxeológica de livro didático de matemática referente ao estudo de números binários. REVEMAT. Florianópolis (SC), v.10, n. 1, p. 199-219, 2015.

MERTENSEN, Marianne. Praxeology as a tool for the analysis of a science museum exhibit. pp. 217-224. In Bosch, M., Gascón, J., Ruiz Olarría, A., Artaud, M., Bronner, A., Chevallard, Y.,Cirade, G., Ladage, C. \& Larguier, M. (Eds.) Um panorama de la TAD. Centre de Recerca Matemática, Campus de Bella-Terra Barcelona, 2011. ISSN: 2014-2323. Eletrônica: 2014-2331. III Congreso Internacional sobre la TAD (Sant Hilari Sacalm, 25-29 enero 2010). 
Recebido: 29 dez. 2015

Aprovado: 15 dez. 2016.

DOI: 10.3895/rbect.v9n1.3657

Como citar: MENDES, H. D. L. Análise praxeológica de livro didático de computação referente ao estudo de números binários. Revista Brasileira de Ensino de Ciência e Tecnologia, v. 9, n. 3, 2016. Disponível em: $<$ https://periodicos.utfpr.edu.br/rbect/article/view/3657>. Acesso em: xxx.

Correspondência:

Direito autoral: Este artigo está licenciado sob os termos da Licença Creative Commons-Atribuição 4.0 Internacional.

\section{(c) (1)}

